\title{
FRP Composites Retrofitting for Protection of Monumental and Ancient Constructions
}

\author{
Alessandro Baratta and Ileana Corbi*
}

Department of Structural Engineering, University of Naples Federico II, via Claudio 2180125 Naples, Italy

\begin{abstract}
The paper presents a short review on some scientific literature developed in the field of protection of historical buildings made of masonry material through the adoption of Fiber Reinforced (FRP) Composites provisions. It mainly focuses on the wide production by the authors, started on the 80 s about masonry constructions and then being continued on retrofitting of monumental constructions by means of FRP from late 90 s up to now.
\end{abstract}

Keywords: Ancient buildings, Preservation, Retrofitting techniques, Masonry, Composites, FRP.

\section{INTRODUCTION}

In an open research field such as preservation of historical masonry heritage, the first step is represented by the development of adequate tools for the response forecast and thereafter the planning of the retrofitting intervention for different types of loads the structure may experience. The reinforcement should obey primary issues relevant to low invasiveness, reliability, robustness and reversibility. Viable candidates in this case are represented by Fiber Reinforced Polymers materials.

A wide literature has been developed on the topic, significantly contributed by the authors during the last decades, which, within the variety of the many features and problems treated, is of relevant interest in terms of advances produced in the specific research area on forecast and protection of masonry constructions.

\section{DEALING WITH MASONRY MONUMENTAL CONSTRUCTIONS}

\subsection{The Protection of Masonry Constructions}

The preservation, protection and restoration [1-4] of masonry constructions has been attracting the research and factory interest for the last decades; this trend is basically due to the circumstance that historical centers and monumental constructions, which are all made of masonry material, usually experience environmental and antropic attacks or changes in their use during their life-cycle that require some kind of interventions for reinforcing the structure, increasing or restoring its full functionality, rising its safety margins that usually decay with time or, anyway, might be not sufficient for suffering exceptional events such as seismic actions, traffic vibrations and so on. On the basis of this premise,

*Address correspondence to this author at the Department of Structural Engineering, University of Naples Federico II, via Claudio 2180125 Naples, Italy; Tel: +390817683926;

E-mail: ileana.corbi@unina.it a number of technologies are under experimentation and testing and have quickly spread out in the professional practice, opening new perspectives for the strengthening of masonry also based on the adoption of composite materials [58]. Actually any intervention strategy should be based on a deep understanding of the behavior of the masonry structure, since it is a complicated system $[9,10]$ deeply related to the operation of the basic material that depends on a number of factors strongly affecting its overall behavior, also including the texture, the arrangement of brick components and structural monads, and the modeling of discontinuities by interface elements [11, 12]. A synthesis of outcomes from a number of studies aimed at formulating the theoretical set up for the analysis of masonry constructions are referred to in the following Sect. 2.2.

\subsection{Investigations on Masonry Structures}

The need of protecting historical and monumental buildings has inspired a wide scientific literature on the subject, with many theoretical as well as experimental contributions and developments of original approaches and techniques and numerical tools for addressing the problem of study of masonry constructions [13-37] and the planning and design of adequate protection techniques.

Conceiving a preservation strategy is not at all a trivial problem when dealing with monumental construction, due to high non-linearity of masonry behavior, complexity of the structure also related to its geometry and need of designing reversible and low invasive provisions, both reliable in the static and in the dynamic ranges.

Besides all of these problems, further problems superpose relevant to difficulties in having at one's disposal effective and completely reliable tools for investigating the masonry behavior itself, especially in the dynamic phase where further nonlinearity is added, but also in some cases in the static range, where often, in common practice, unreliable linear or non-linear simple elastic models are adopted and forced to comply with masonry characteristics instead of 
adopting more proper No-Tension (NT) or Low Tension (LT) models.

Actually the basis for any study concerning masonry structures and for planning any protection or safeguard strategy consists of correctly approaching the problem by adopting a proper modeling of the structure in the static range, which may refer, for example, to the mentioned NT assumption.

The basic assumption of No-Tension masonry model coincides with the hypothesis that the tensile resistance is null. Under this hypothesis, no-tension stress fields are selected by the body through the activation of an additional strain field, the fractures (see [13-17]).

The behavior in compression can be modeled in a number of different ways (elastic linear, elastic non-linear, elastic-plastic; isotropic, anisotropic; etc.) without altering substantially neither the results nor the mathematical treatment of the problem; some convenience exists for practical applications in assuming a isotropic linearly elastic model, in order to keep limited the number of mechanical parameters to be identified for masonry, since increasing the number of data causes increasing uncertainty in the results. Because of these reasons, and being clearly understood that there is no difficulty in introducing more sophisticated models, it is convenient to set up the fundamental theory on the basis of the assumption that the behavior in compression is indefinitely linearly elastic.

Analysis of NT (No-Tension) bodies proves that the stress, strain and displacement fields obey extreme principles of the basic energy functionals.

Therefore the behaviour of NT solids under ordinary loading conditions can be investigated by means of some extensions of basic energy approaches to NT bodies [16, 18, $30]$, and it can be usefully applied also for the study of stress diffusion of non-cohesive materials like soils [38, 39].

In details, the solution of the NT structural problems can be referred to the two main variational approaches: i) the minimum principle of the Potential Energy functional and ii) the minimum principle of the Complementary Energy functional properly extended for treating NT structures.

The solution of both problems can be numerically pursued by means of Operational Research methods (see i.e. [40]) suitably adopting discrete models of the analyzed NT continuum [30, 31]. One should notice that discussion about existence of the solution actually can be led back to some Limit Analysis of the considered NT continua [17, 19, 22, 24] and the individuation of the collapse (live) load multiplier for NT continua can be referred to the approaches relying on the two main limit analysis static and kinematic theorems, suitably extended to the NT case.

Duality tools may also be successfully applied in order to check the relationships between the two theorems of Limit Analysis [26, 27]. In the study of plane mono-dimensional structures featuring a low degree of redundancy, the force/stress approach appears the most convenient to be adopted if compared with the displacement/strain approach, whose number of governing variables is higher and, moreover, increasing with the order of discrete mesh [28].
Numerical results and comparison with experimental data show that the proper implementation of the described theoretical approach for classical masonry structural typologies such as panels, arches and vaults, produces results that are in a very good agreement with laboratory experiments, demonstrating the overall reliability of the mentioned approach, for whose details one should refer to cited references.

\section{PRESERVATION OF MONUMENTAL CON- STRUCTIONS THROUGH FRP INTERVENTIONS}

\subsection{General Premises}

The need of protecting monumental masonry constructions in historical urban centers has pushed towards the development of innovative refurbishment techniques and adaptation interventions. As described in the previous section, set up of proper theoretical tools for studying masonry constructions represents the necessary premise for reliable forecasts on behavior of structures and predictions even in dynamic phase where also control strategies [41-45] may be planned, especially useful in the absence of environmental forecasts $[46,47]$ and for vulnerability assessment [48, 49]

Therefore valid alternatives to ordinary refurbishment techniques are nowadays offered by the factory with the development of new materials, such as composites; composites lend themselves to pre-damage and post-damage strategies and are particularly suitable for ancient constructions since they are able to provide effective and low invasive reinforcement interventions (see ref. [50-55]), even if further advances both in theoretical and experimental features are still required.

High strength in tension and low flexural rigidity, low weight, good resistance to chemical attacks, low invasiveness and reversibility characterizing Fibre Reinforced Polymers (FRPs), make them viable candidates for increasing the mechanical resistance of structures with very low tensile resistance, such as masonry, in the respect of the original structural apparatus of the ancient constructions.

The effectiveness of the provision is largely dependent on the right orientation of the fibres, which should optimally exploit the high anisotropy of fibres in order to compensate the low tensile resistance of structural masonry elements.

Therefore any intervention should be designed according to the expected behaviour and collapse modes of the structure.

\subsection{Design and Investigations of Masonry Arched and Vaulted Structures Reinforced by FRP}

The research developed on the subject at the University of Naples has concerned both design issues, theoretical set up, developments of theoretical and numerical tools, formulation of some original calculus codes and laboratory experiments; all of these work-stages have been aimed at investigating and reliably forecasting the response of a number of classical masonry typologies under the NT assumption reinforced or not by means of FRP composites, and at providing design issues for FRP provisions to be applied on masonry structures. 
The validation of the theoretical models of the masonry reinforced or not with different types of FRP provisions has been performed by comparison with experimental data; it represents a very important feature of this research, since one should emphasize that, up to now, very few research may be found in literature where a numerical/ experimental comparison is presented, moreover with such a good agreement of data.

In major details, in the mentioned research, some results proving the successful application of a correct theoretical treatment, based on the NT material assumption, of structural problems relevant to classical masonry typologies such as arches, walls and vaults reinforced with different types of FRP provisions have been developed.

The set up of the general energetic approach for analyzing reinforced masonry structures under live loads, its specialization to the relevant discrete models, the implementation of ad hoc built up calculus codes have been demonstrated to produce numerical results in very good agreement with data produced by experimental investigation.

As regards theoretical modelling, one should observe that, differently from many models which require a number of parameters allowing a certain adaptation of the shape of the numerical curve to the experimental one, the NT model has the big advantage that the only mechanical parameter to be evaluated is the masonry elastic modulus. Since the tuning of the theoretical model is rather simple, there would be no possibility to force it to produce theoretical results fitting with such a good agreement the experimental data, because the tuning operation itself cannot influence the shape of the numerical diagram but only the displacements scale.

As a point of fact, the sensitivity of the modelling to material assumptions is reduced to the inverse proportionality between the material elastic modulus and the displacements, without any influence on the load capacity and on the evolution of displacements with the loads.

Actually the extension of the theoretical tools to the case of some reinforcement directly applied on the masonry has been studied by properly modeling the reinforcement itself within the calculus codes developed for analyzing the masonry structures and the connection of the reinforcement with the masonry, thus producing additional codes accounting for the different types of provisions.

The theoretical/numerical agreement, which, as mentioned in the above, up to now is an original result for the case of masonry constructions with FRP reinforcements, has demonstrated that the overall theoretical approach is reliable for the treatment of masonry constructions also in the presence of consolidation interventions made of FRP, and it is very useful for forecasts about the reinforced behavior of the structure.

Issues for the design of FRP provisions have been derived depending on the single structure typology and on the expected collapse modes.

With reference to the case of arched or vaulted structures, as well known, the proneness to collapse is, in most cases, dependent on the activation of cracking mechanisms; in order to prevent the structure from the formation of a number of unilateral hinges such to activate a collapse mechanism during a seismic motion, one has studied the behavior of masonry arches and vaults subject to horizontal and vertical loads and one has adopted FRP reinforcements placed on the structure in such a way to prevent the activation of some hinges and therefore of the overall mechanism.

The reinforcements have then been introduced in the form of strips of variable length covering the arch depth, and glued on it by means of special resins. The strips have been applied on the arch intrados or extrados at different locations, depending on the expected side of crack opening, at the cross-sections where hinges are supposed to be activated.

Some pictures taken during experiments are reported in Figs. (1 and 2), with the adopted loading and monitoring equipment.

From a theoretical point of view, concerning the theoretical set up of the problem, this type of provision does not introduce any additional redundancy in the problem, but acts on the constraint conditions relevant to material admissibil-
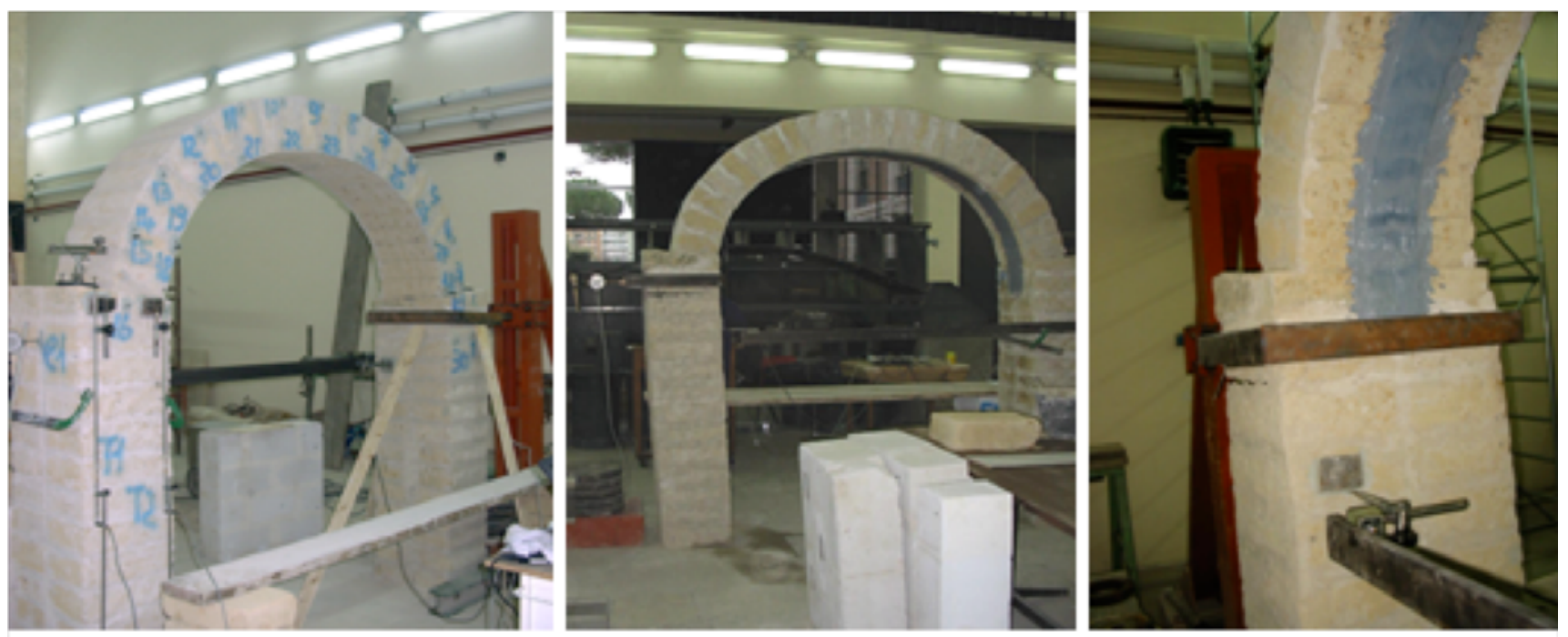

Fig. (1). Pictures of masonry portal arches reinforced by FRP during laboratory tests at the University of Naples. 
ity. The primary effect is then that the funicular line is enabled to come out, along the surfaces where the FRP is applied, from the arch or vault profile on the side opposite to the side where the FRP strip is applied.

Therefore one or more of the admissibility constraints are relaxed thanks to the presence of the FRP at the crosssections where the strips are present, resulting in the increasing of the carrying capacity of the structure.

Actually the adopted FRP provisions have been shown to be able to highly increase the original loading capacity of the structure and to change the collapse mechanisms of the structure; an excellent agreement of numerical data with experimental results has been obtained.

\subsection{Design and Investigations of Masonry Walls Rein- forced by FRP}

As regards to masonry walls, horizontal and vertical loads have been considered as well, acting on panels whose tuff bricks are connected or not by mortar, in which case a major adherence does exist with the theoretical NT model, and different types of FRP provisions have been conceived for mitigating the stress diffusion in the panels by bonding some strips on the masonry.

Some of the provisions are rather light in order to allow to appreciate the increasing in the overall rigidity of the panels contributed by the FRP strips.

Some pictures taken during experiments are reported in Figs. (3 and 4), with the adopted loading and monitoring equipment.

Even in this case the theoretical set up of the problem has been formulated in such a way to include the FRP provisions, and compare results, at the subsequent research stage, with the laboratory tests developed on the masonry panels with a central hole reported in Figs. (3 and 4), which are subjected to a tensile horizontal action applied at the top of the right side.

The adopted consolidation technique has consisted of gluing some strips made of fibre reinforced material on the main masonry structure, enwrapping the wall abutments with FRP strips, or introducing vertical strips, or coupling both
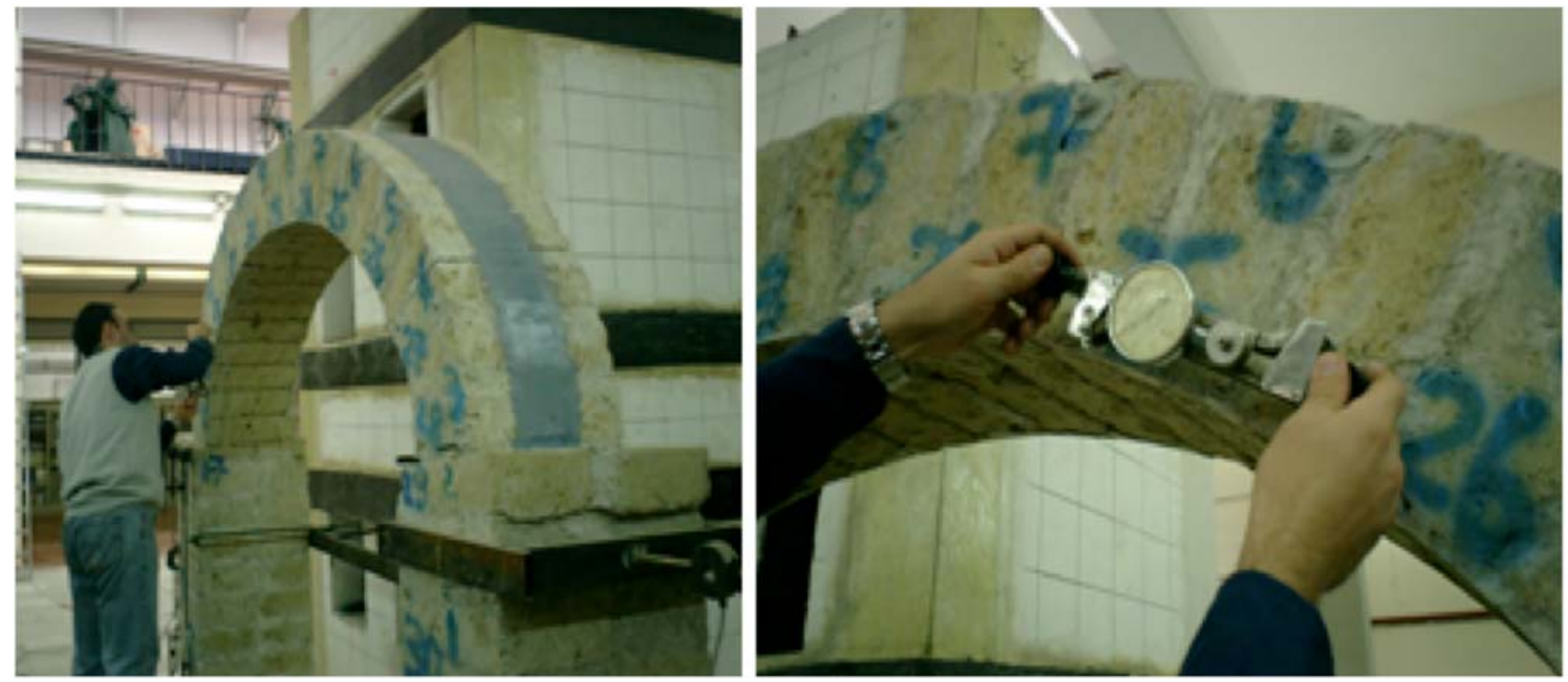

Fig. (2). Pictures of masonry portal arches reinforced by FRP during laboratory tests at the University of Naples.
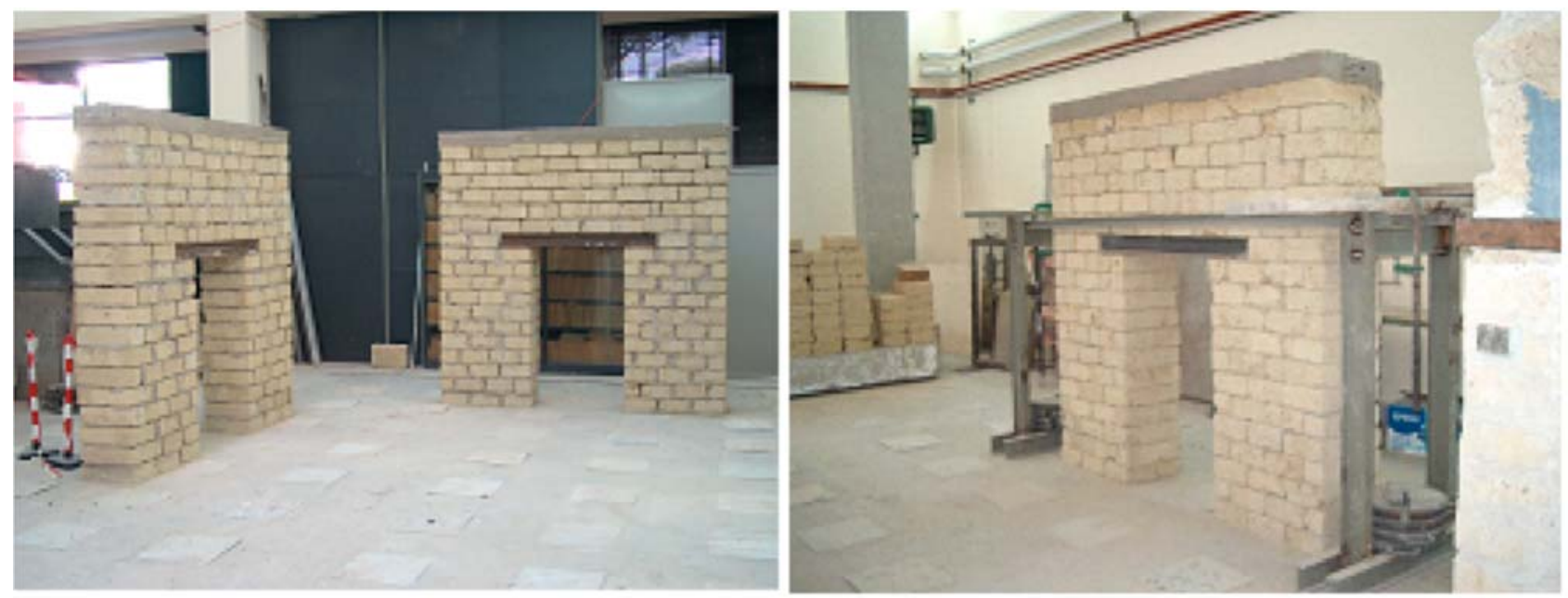

Fig. (3). Pictures of masonry panels during laboratory tests at the University of Naples (2003). 

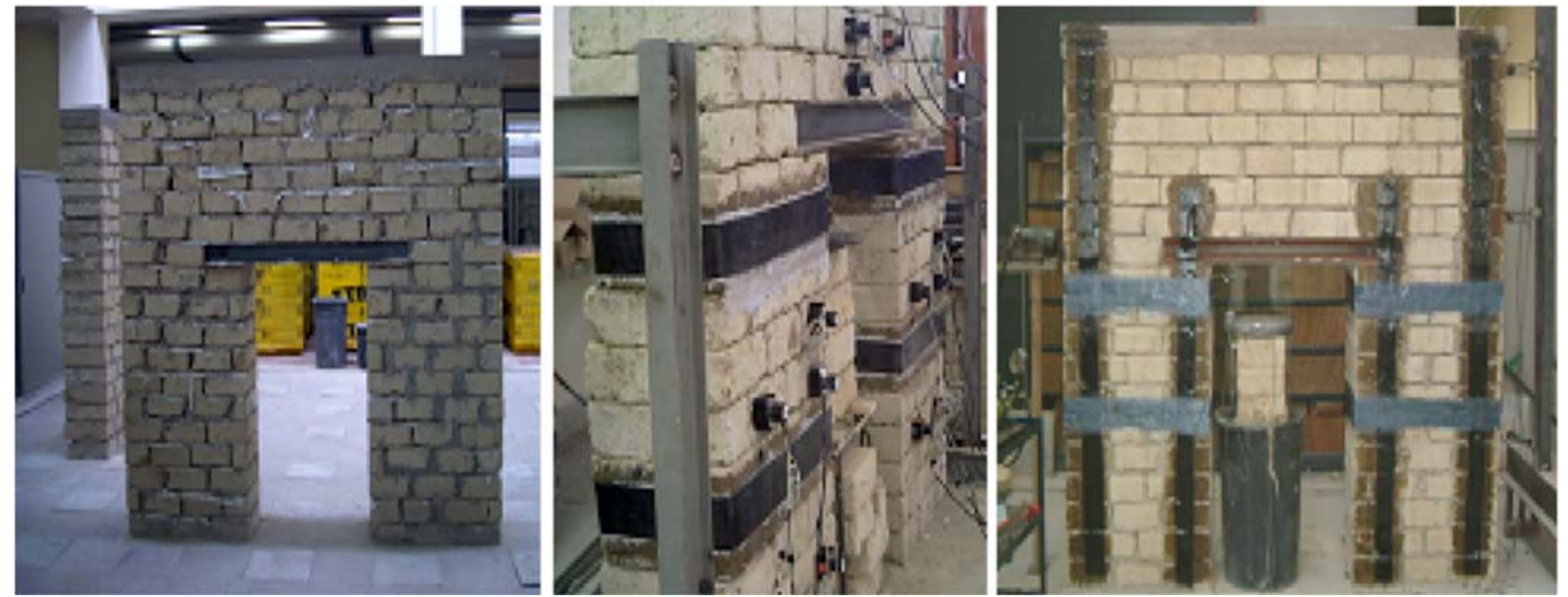

Fig. (4). Pictures of masonry panels during laboratory tests at the University of Naples (2003).

provisions.

As concerns the case of the light horizontal reinforcement of pillars, in the wall without mortar a distributed opening of joints has occurred between bricks in the nonreinforced areas exhibiting a global lifting of the panel; this effect is more mitigated in the walls with mortar.

This is the reason why new types of reinforcements have been introduced consisting of simple vertical strips or vertical strips overlapped to the horizontal ones.

Comparison of data recorded during laboratory tests has shown that the panel without mortar exhibits an overall lower bearing strength than the panel with mortar and that the panel's strength increases in the case of the reinforced panel with mortar. In general, the major effect of the application of reinforcement has consisted of the reduction of stresses in the masonry with lower shifts exhibited during tests, of the increasing of the rigidity of the wall and of the collapse load.

A major increasing of stiffness and collapse load has been appreciated in the coupled vertical/horizontal FRP reinforcement.

Even in the case of light reinforcement, the calculus codes have been able to capture the decreasing in the stress state in the masonry due to the FRP provisions, and the increasing in the rigidity and carrying capacity of the structure. Good agreement has been checked between the results of experimental investigations with the theoretical forecasts, both in the not-consolidated and in the consolidated cases, and for the panels with and without mortar.

\section{CONCLUSIONS}

In the paper one addresses some problems relevant the reinforcement of monumental ancient constructions made of masonry material, involving some theoretical, numerical and experimental issues. A review of some activities developed at the University of Naples is reported, both concerning experimental tests, numerical investigations, and theoretical validation of the provided formulations performed by comparison of numerical and experimental data. Tests show high effectiveness of FRP provisions on different masonry typologies, when the intervention is properly conceived. The excellent agreement of theoretical and experimental results is an original result, and very few research up to now can be found in literature to this regard.

\section{ACKNOWLEDGEMENTS}

The present research has been supported by MIUR and by funds of the Campania Regional Administration for the realization of the masonry walls which have been tested during 2003. The BETONTEX srl (now Edilan srl) have supported the reinforcement on the masonry arches and walls consisting of some carbon fibres strips and a polymeric resin.

\section{CONFLICT OF INTEREST}

The authors confirm that this article content has no conflicts of interest.

\section{REFERENCES}

[1] P.G. Asteris, A.D. Tzamtzis, P.P. Vouthouni, and D.S. Sophianopoulos, "Earthquake resistant design and rehabilitation of masonry historical structures", Practice Periodical on Structural Design and Construction, American Society of Civil Engineers (ASCE), vol. 10, no. 1, pp. 49-55, 2005.

[2] P.G. Asteris, "On the structural analysis and seismic protection of historical masonry structures", The Open Construction and Building Technology Journal, vol. 2, pp.124-133, 2008.

[3] L. Binda, C. Modena, G. Baronio, and S. Abbaneo,"Repair and investigation techniques for stone masonry walls", Construction and Building Materials, vol. 11, no. 3, pp. 133-42, 1997.

[4] L. Binda, and A. Saisi, "Research on historic structures in seismic areas in Italy", Progress in Structural Engineering and Materials, vol. 7 , no. 2 , pp.71-85, 2005.

[5] T.D. Krevaikas, and T.C. Triantafillou, "Masonry confinement with fiber-reinforced polymers", Journal of Composites for Construction, vol. 9, no. 2, pp. 128-135, 2005.

[6] S. Rocca, M. Ekenel, N. Galati, B. Gerber, and T. Alkhrdaji, "Recent revisions to acceptance criteria for concrete and masonry strengthening using externally bonded FRP systems" (AC125), American Concrete Institute, ACI Special Publication, vol. 2 no. 275 SP, pp. 825-839, 2011.

[7] F.J. Pallarés, S. Ivorra, L. Pallarés, and J.M. Adam, "State of the art of industrial masonry chimneys: A review from construction to strengthening", Construction and Building Materials, vol. 25, no. 12, pp. 4351-4361, 2011. 
[8] B. Ghiassi, G. Marcari, D.V. Oliveira, and P.B. Lourenço, "Numerical analysis of bond behavior between masonry bricks and composite materials ", Engineering Structures, vol. 43, pp. 210$220,2012$.

[9] C.A. Syrmakezis, and P.G. Asteris, "Masonry failure criterion under biaxial stress state", Journal Of Materials in Civil Engineering; American Society of Civil Engineers (ASCE), vol. 13, no. 1, pp. 58-64, 2001.

[10] P.B. Lourenço, "Computations on historic masonry structures", Progress in Structural Engineering and Materials, vol. 4, no. 3, pp. 301-19, 2002.

[11] P.G. Asteris, and A.D. Tzamtzis, "Nonlinear seismic response analysis of realistic gravity dam-reservoir systems", International Journal of Nonlinear Sciences and Numerical Simulation, vol. 4, no. 4, pp. 329-338, 2003.

[12] F. Fouchal, F. Lebon, and I. Titeux, "Contribution to the modelling of interfaces in masonry construction", Construction and Building Materials, vol. 23, no. 6, pp. 2428-2441, 2009.

[13] J. Heyman, "The stone skeleton", Journal of Solids and Structures, vol. 2, pp. 269-279, 1966.

[14] J. Heyman, "The safety of masonry arches", Journal of Mechanic Sciences, vol. 2, pp. 363-384, 1969.

[15] A. Baratta, "Statics and reliability of masonry structures", In: General Principles Applications in Mechanics of Solids and Structures. CISM, Udine, pp. 205-235, 1991.

[16] A. Baratta, M. Vigo, and G. Voiello, "Calcolo di archi in materiale non resistente a trazione mediante il principio del minimo lavoro complementare". Proc. $1^{\text {st }}$ Nat. Conf. ASS.I.R.C.CO. Verona, 1981.

[17] Z.P. Bazant, "Analysis of work-of fracture method for measuring fracture energy of concrete", Journal of Engineering Mechanics ASCE, vol. 122, no. 2, pp.138-144, 1996.

[18] A. Baratta, "Il materiale Non Reagente a Trazione come modello per il calcolo delle tensioni nelle pareti murarie", Journal of Restauro, vol. 75, pp. 53-77, 1984.

[19] M. Como, and A. Grimaldi, "A unilateral model for Limit Analysis of masonry walls", In: Unilateral Problems in Structural Analysis, Ravello, pp. 25-46, 1983.

[20] Z.P. Bazant, and Y.N. Li, "Stability of cohesive crack model: Part I: Energy principles", Journal of Applied Mechanics. vol. 62, no. 12, pp. 959-964, 1995.

[21] R.W. Odgen, Non linear elastic deformations. Dover Publications Inc.: Mineola, New York, 1997.

[22] A.M. Khludnev, and V.A. Kovtunenko, "Analysis of cracks in solids", Applied Mechanics Review, vol. 53, no. 10, 2000

[23] A. Baratta, I. Corbi, and O. Corbi, "Stress analysis of masonry structures: Arches, walls and vaults", Proceedings of the 6th International Conference on Structural Analysis of Historic Construction: Preserving Safety and Significance, SAHC08;Bath; 2 July 2008-4 July 2008;Code83644, vol.1, pp.321-329, 2008. ISBN: 0415468728; 978-041546872-5.

[24] A. Baratta, and O. Corbi, "An approach to masonry structural analysis by the no- tension assumption-Part I: material modeling, theoretical setup, and closed form solutions", Applied Mechanics Reviews, vol. 63, no. 4, pp. 040802-1/17, 2010. ISSN: 0003-6900, DOI:10.1115/1.4002790.

[25] A. Baratta, and O. Corbi, "An approach to masonry structural analysis by the no-tension assumption-Part II: load singularities, numerical implementation and applications". Applied Mechanics Reviews, vol. 63, no. 4, pp. 040803-1/21, 2010. ISSN: 0003-6900, DOI:10.1115/1.4002791.

[26] A. Baratta, and O. Corbi, "Relationships of L.A. theorems for NRT structures by means of duality". International Journal of Theoretical and Applied Fracture Mechanics, Elsevier Science, vol. 44, pp. 261-274, 2005. ISSN: 0167-8442.

DOI:10.1016/j.tafmec.2005.09.008.

[27] A. Baratta, and O. Corbi, "Duality in non-linear programming for limit analysis of NRT bodies", Structural Engineering and Mechanics, An International Journal, Technopress. vol. 26, no. 1, pp. 15-30, 2007. ISSN: 1225-4568.

[28] A. Baratta, and O. Corbi, "On the equilibrium and admissibility coupling in NT vaults of general shape", International Journal of Solids and Structures, vol. 47, no. 17, pp. 2276-2284, 2010. ISSN: 0020-7683. DOI: 10.1016/j.ijsolstr.2010.02.024.

[29] A. Baratta, "Strength capacity of No Tension portal arch-frame under combined seismic and ash loads", Journal of Volcanological and Geothermal Research, vol. 133, no. 1-4, pp. 369-376, 2004 ISSN: 0377-0273, DOI: 10.1016/S0377-0273(03)00408-6.

[30] A. Baratta, and I. Corbi, "Iterative procedure in no-tension 2D problems: theoretical solution and experimental applications", In: G.C. Sih and L. Nobile Eds., In: Proceedings of the International Conference on Restoration, Recycling and Rejuvenation Technology for Engineering and Architecture Application; Cesena, Code64053, 7-11 June 2004, pp. 67-75. ISBN: 8879997653.

[31] A. Baratta, and O. Corbi, "On variational approaches in NRT continua", International Journal of Solids and Structures, Elsevier Science, vol. 42, pp. 5307-5321, 2005. ISSN: 0020-7683.

DOI:10.1016/j.ijsolstr.2005.03.075.

[32] A.W. Maunder, "Limit analysis of masonry structures based on discrete elements", In: C.A. Brebbia, R.J.B. Frewer (eds) Structural repair and maintenance of historical buildings III. Computational Mechanics Publications, Southampton, pp. 367-374, 1993.

[33] C. Molins, and P. Roca, "Capacity of masonry arches and spatial frames", Journal of Structural Engineering (ASCE), vol. 124, no. 6, pp. 653-663, 1998.

[34] A. Baratta, and O. Corbi, "On the statics of No-Tension masonrylike vaults and shells: solution domains, operative treatment and numerical validation", Annals of Solid and Structural Mechanics, vol. 2. no. 2-4, pp. 107-122, 2011. ISSN: 0965-9978. DOI: 10.1007/s12356-011-0022-8.

[35] A. Baratta, and I. Corbi, "On the statics of masonry helical staircases", In: B.H.V. Topping, Y. Tsompanakis, (Eds), Proceedings of the Thirteenth International Conference on Civil, Structural and Environmental Engineering Computing, Civil-Comp Press, Stirlingshire, UK, Crete; 6 -9 September 2011, Paper 59. ISBN: 978-190508845-4, DOI:10.4203/ccp.96.59.

[36] D. Foti, "On the numerical and experimental strengthening assessment of tufa masonry with FRP", (in press) Mechanics of Advanced Materials, 2012, ISSN 1558-3066.

[37] D. Foti, S. Ivorra-Chorro, and M.F. Sabba, "Dynamic investigation of an ancient masonry bell tower with operational modal analysis", in press on The Open Construction and Building Technology Journal, 2012. [Epub ahead of print].

[38] A. Baratta, and I. Corbi, "Plane of elastic non-resisting tension material under foundation structures", International Journal for Numerical and Analytical Methods in Geomechanics, J. Wiley \& Sons Ltd., vol. 28, pp. 531-542, 2004. ISSN: 0363-9061, DOI: 10.1002/nag.349.

[39] A. Baratta, and I. Corbi, "Spatial foundation structures over notension soil", International Journal for Numerical and Analytical Methods in Geomechanics, Wiley Ed. vol. 29, pp. 1363-1386, 2005. ISSN: 03639061, DOI: 10.1002/nag.464.

[40] S.S. Rao, Optimization: Theory and applications, Wiley \& Sons: New Delhi, 1978.

[41] A. Baratta, and O. Corbi, "Dynamic response and control of hysteretic structures", International Journal of Simulation Modeling Practice and Theory (SIMPAT), Elsevier Science, vol. 11, pp. 371385 , 2003. ISSN: 1569-190X, DOI: 10.1016/S1569190X(03)00058-3.

[42] A. Baratta, and O. Corbi, "On the dynamic behaviour of elasticplastic structures equipped with pseudoelastic SMA reinforcements", Journal of Computational Materials Science, vol. 25, no. 1-2, pp. 1-13, 2002. ISSN: 09270256, DOI: 10.1016/S09270256(02)00245-8.

[43] A. Baratta, and I. Corbi, "Optimal design of base-isolators in multistorey buildings", International Journal of Computers \& Structures, Elsevier, vol. 82, no. 23-26, pp. 2199-2209, 2004. ISSN: 00457949, DOI: 10.1016/j.compstruc.2004.03.061.

[44] A. Baratta, and O. Corbi, "Analysis of the dynamics of rigid blocks using the theory of distributions", Advances in Engineering Software, vol. 44, no. 1, pp. 15-25, 2012. ISSN: 09659978CODEN, DOI: 10.1016/j.advengsoft.2011.07.008.

[45] A. Baratta, I. Corbi, and O. Corbi, "Rocking motion of rigid blocks and their coupling with tuned sloshing dampers", In: B.H.V. Topping, L.F. Costa Neves, and R.C. Barros, (Editors). In: Proceedings of the Twelfth International Conference on Civil, Structural and Environmental Engineering Computing, Civil-Comp Press, Stirlingshire, UK, 2009, Paper 175. ISBN: 978-1-9050-88-32-4, DOI: $10.4203 /$ ccp. 91.175 .

[46] A. Baratta, and I. Corbi, "Epicentral distribution of seismic sources over the territory", International Journal of Advances in Engineer- 
ing Software, Elsevier vol. 35, no. 10-11, pp. 663-667, 2004. ISSN: 0965-9978, DOI: 10.1016/j.advengsoft.2004.03.015.

[47] A. Baratta, and I. Corbi "Evaluation of the hazard density function at the Site", International Journal of Computers \& Structures, Elsevier, vol. 83, no. 28-30, pp. 2503-2512, 2005. ISSN: 0045-7949, DOI: $10.1016 /$ j.compstruc.2005.03.038

[48] A. Baratta, I. Corbi, and S. Coppari, "A method for the evaluation of the seismic vulnerability of fortified structures", Final Conference on COST Action C26: Urban Habitat Constructions under Catastrophic Events; Naples, Code89987, 16 -18 September 2010, pp. 547-552. ISBN: 978-041560685-1.

[49] A. Baratta, I. Corbi, O.Corbi, and D. Rinaldis, "Experimental survey on seismic response of masonry models", Proceedings of the 6th International Conference on Structural Analysis of Historic Constructions: Preserving Safety and Significance, SAHC08, Bath; Code83644, vol. 2, 2-4 July 2008, pp. 799-807. ISBN 0415468728;978-041546872-5.

[50] G. Schwegler, "Masonry construction strengthened with fiber composites in seismically endangered zones", Proc. $1^{\text {th }}$ European Conference of Earthquake Engineering, Vienna, 1994.
[51] T.C. Traintafillou, "Innovative Strengthening of Masonry Monuments with Composites", Proceeding of $2^{\text {nd }}$ International Conference Advanced Composite Materials in Bridges and Structures, Montréal, 1996.

[52] F. Ascione, "Ultimate behaviour of adhesively bonded FRP lap joints", Journal of Composites Part B, Engineering, vol. 40, pp. 107-115, 2009. ISSN: 1359-8368, doi: 10.1016/j.compositesb.2008.11.006.

[53] M. El-Badry, "Advanced composite materials bridges and structures", Proceeding of $2^{\text {nd }}$ International Conference Advanced Composite Materials in Bridges and Structures, Montréal, 1996.

[54] D. Brigante, Rinforzo Strutturale Con Materiali Compositi, pp. 152 con software, Grafill ISBN: 88-8207-461-6, 2012.

[55] A. Baratta, and I. Corbi, "Optimal reinforcement for no-tension structure" In: F. Ubertini, E. Viola, S. de Miranda, G. Castellazzi (eds) Atti del $20^{\circ}$ Convegno Nazionale di Meccanica Teorica e Applicata AIMETA, Publi\&Stampa Edizioni, Conselice (Ra), paper no. 249, 12-15 Settembre 2011, pp. 10. ISBN: 978-88-906340-1-7.

Received: October 18, 2012

Revised: October 31, 2012

Accepted: October 31, 2012

(C) Baratta and Corbi: Licensee Bentham Open.

This is an open access article licensed under the terms of the Creative Commons Attribution Non-Commercial License (http://creativecommons.org/licenses/ by-nc/3.0/) which permits unrestricted, non-commercial use, distribution and reproduction in any medium, provided the work is properly cited. 